\title{
Understanding the Relationship between Humanitarian and Development Interventions: A Mixed-Methods Systematic Review Protocol
}

\author{
Garry Stevens $^{1 *}$, Nidhi Wali, Nichole Georgeou and Zulfan Tadjoeddin \\ ${ }^{1}$ Humanitarian and Development Research Initiative (HADRI), School of Social Sciences and \\ Psychology, Western Sydney University, Australia
}

\begin{abstract}
The rising number of natural disasters and emergent conflicts that require coordinated international response has re-focused attention on linking relief, rehabilitation and development (LRRD). This systematic review protocol aims to inform a systematic review to identify primary operational strategies employed to link humanitarian and development interventions. This protocol is guided by Preferred Reporting Items for Systematic Reviews and Meta-Analyses Protocols (PRISMA) guidelines and details the review scope and parameters. Findings from this review can contribute to articulation of an integrated LRRD practice framework and its potential application to resilience and related policy instruments.
\end{abstract}

Keywords: Humanitarian, Development, Linking, Relief, Rehabilitation, Resilience, Grand Bargain

\section{Background}

The concept of linking relief, rehabilitation and development (LRRD) emerged in the 1980s when practitioners identified a funding gap between humanitarian assistance, relief, and development activities. The Ethiopian famine of 1983-85 brought this issue into sharp focus and highlighted the critical need to link short-term relief and longer-term development programs (Mosel \& Levine, 2014). It was argued that doing so would create synergies between these historically separated forms of aid and provide a more sustainable response to periodic crises (European Parliament, 2012).

LRRD has been described as 'intuitively simple' (Mosel \& Levine, 2014) and was initially conceived as a 'continuum' model - a linear one-way transition from an emergency relief phase back to a pre-disaster development course, with rehabilitation often regarded as a 'bridge' between these phases. The model provided important recognition that humanitarian need, poverty and state fragility are inter-related and often occur concurrently (Otto \& Weingärtner, 2013). In this sense, better 'development' can reduce long-term relief needs, while well-targeted relief programs can support community development. Conceived in this form however, it often served to reinforce existing aid structures and cultures where disasters

\footnotetext{
${ }^{*}$ Corresponding author Dr. Garry Stevens, Humanitarian and Development Research Initiative (HADRI), School of Social Sciences and Psychology, Western Sydney University, Locked Bag 1797, Penrith 2751, New South Wales, Australia. Email:

G.Stevens@westernsydney.edu.au
} 
were typically regarded as 'outliers', or disrupters to the 'normal' development path, while relief practitioners largely saw operating links as supporting their exit strategies from current operations.

The earlier linear approach to LRRD failed to respond to the complexity of protracted humanitarian emergencies of the 1990s where changing operational environments made it difficult to respond to each phase separately or in a step-wise fashion (Duffield, 1994). Socalled 'second generation' or 'contiguum' models were advocated during this period, which recognised the need for often simultaneous and complimentary use of different aid instruments, subject to the needs of time and region (Duffield, 1994; Longhurst, 1994). ${ }^{2}$ It has been further argued that, rather than linking different kinds of aid instruments/functions, a fundamentally different model of long-term engagement may be needed; one that may not incorporate traditional aid instruments at all, and which can deal holistically with protracted and recurrent crises that reflect the normality of destabilised regions (Mosel \& Levine, 2014).

Other developments since 2000 have seen security policy actors argue that LRRD needs to support security transitions out of State fragility and a greater strategic coherence between security, development and humanitarian assistance (Harmer \& Macrae, 2004). This realignment of humanitarian and development assistance with security objectives is evident in recent policy instruments such as the European Commission's Instrument contributing to Stability and Peace (IcSP) and Canada's Stabilization and Reconstruction Task Force (START). These place humanitarian assistance within the broader framework of conflict prevention, peace-building and capacity building for long-term socio-economic development.

An enduring challenge in operationalising LRRD at structural and program levels relates to the need to reconcile the fundamentally different cultures, structures, values and ways of working that have historically characterised the humanitarian and development fields. Macrae (2012) argues these have been increasingly bifurcated since the 1980s, with development agencies continuing to work through governments to strengthen their systems and institutions, while humanitarian practitioners increasingly sought to work around uncooperative governments to provide emergency relief. Macrae (2012) further cautions against their potential loss of independence and neutrality through close alignment with government, particularly in conflict settings.

In more practical terms, there has been a lack of clarity and consensus about the problems the LRRD concept seeks to resolve. Streets (2011) argues that the common view supporting the model of a temporal funding gap between humanitarian and development phases has proven untenable. Moreover, Otto and Weingärtner (2013) highlight that there are no agreed definitions about what the concept - or its constituent components of relief, rehabilitation and development - means, nor are there any accepted operational definitions of their beginning, end or working integration. Although LRRD is commonly endorsed at the Policy level (European Commission, 2007; European Parliament, 2012), recent evaluations indicate that it is only applied on a case-by-case basis (Morazán, Grünewald, Knoke, \& Schäfer, 2012). The multi-agency Tsunami Evaluation Commission (TEC) found little evidence that LRRD, as a principle, had driven programming at a practice level (Brusset, Pramana, Davies, Deshmukh, \& Pedersen, 2006; Goyder et al., 2006) finding LRRD policies were seen as 'too vague and disconnected from practice to make any tangible difference' (Christoplos, Novaky, \& Aysan, 2012).

${ }^{2}$ While later descriptions of LRRD approaches frequently refer to the simultaneous or 'integrated' use of humanitarian and development instruments, the convention used in this paper is to refer to the linking of these aid instruments and the processes by which this occurs.

Social Science Protocols, December 2018, 1-12.

http://dx.doi.org/10.7565/ssp.2018.2649 
More recent policy frameworks and initiatives including 'resilience', 'disaster risk reduction' and the early recovery concepts and 'clusters' of groups such as UNDP, have provided renewed interest in LRRD. Resilience concepts are somewhat broader than those captured by LRRD models, focusing not only on those in crisis and the Aid instruments that support them, but also those vulnerable to crises and how their adaptive capacities can be supported and developed. Disaster Risk Reduction (DRR) can be seen as a practical application of the resilience concept. This approach supports community-based education and risk reduction measures regarding hazards and disasters, but also attempts to re-focus development activities towards greater risk-sensitivity and proactive response. The largely technical approach of DRR has been criticised as being 'politically blind' to the societal conditions underpinning vulnerability (Mosel \& Levine, 2014), however it has achieved notable community outcomes (Christoplos et al., 2012; Twigg, 2015). Importantly, LRRD has been seen as a potential framework that can support the integration of disaster risk reduction within development assistance; so-called DRR 'mainstreaming' (Jones, Oven, Manyena, \& Aryal, 2014). Groups such the Global Network of Civil Society Organizations for Disaster Reduction (GNDR) have emphasised that vulnerable communities must be centrally involved in such disaster risk governance and management, particularly in that they can advocate and support the pragmatic linking of aid instruments in a way that often evades traditional State and international actors (Botha \& van Niekerk, 2013).

A key focus of the discourse around resilience has been about having a different way of thinking about development in protracted crises and how to provide sustained support to those who are most vulnerable. Rather than a competing paradigm, resilience similarly addresses the need to bring development and humanitarian actors together to achieve these outcomes. However, there remains a substantial debate about how to operationalise resilience strategies. In North America these issues are more often addressed via 'developmental relief' frameworks, with funding instruments such as USAID's Transition Initiatives providing recent examples of strategic integration (Khalil \& Zeuthen, 2014).

\subsection{The Grand Bargain}

The Grand Bargain was created to address the discrepancy between funds needed and funds provided in the humanitarian relief sector. It can be understood as an effort to bridge this gap that combines donor states and large International NGOs (INGOs). It is essentially a compact of donors and service providers that aims to provide greater coordination of relief efforts. The original Agreement discussed in 2015 was between five large donors and the six largest UN agencies, but the May 2016 Grand Bargain Agreement expanded to include eighteen donors and sixteen INGOs (Metcalfe-Hough \& Poole, 2018). The Grand Bargain 'Sherpas' (negotiators) eventually agreed on a total of fifty-one mutual commitments, divided into ten Work streams. Five of the fifty-one commitments relate to Work Stream Ten: 'Enhance engagement between humanitarian and development actors'. An independent report commissioned to gauge progress on the Grand Bargain noted Work Stream Ten was one of the seven areas in which this new agenda was graded as offering only 'some progress'. The report gave Work Stream Ten- two out of four stars in all criteria assessed: donor activity; aid organisation activity; activity on joint commitments; links to other work streams; and links to other existing processes. (Metcalfe-Hough \& Poole, 2018)

Work Stream Ten has presented difficulties for the Sherpas, and it seems the idea of enhancing engagement between humanitarian and development actors was deemed as being too complex to be managed within the Grand Bargain framework. Regarded by donors as a "cross-cutting issue", Work Stream Ten was eventually closed in March 2018 at the request

Social Science Protocols, December 2018, 1-12. http://dx.doi.org/10.7565/ssp.2018.2649 
of the co-conveners UNDP and Denmark (Metcalfe-Hough \& Poole, 2018, p. 60). Some signatories to the Grand Bargain however remain interested in continuing the work of bridging this gap, stressing that it is vital to achieve some effective linkage of these fields. One large (unnamed) donor "raised serious concerns" that the momentum gained around this issue would be lost (Metcalfe-Hough \& Poole, 2018, p. 60). We review below recent efforts to align humanitarian and development actors and their operational frameworks.

\subsection{Progress to date}

In Europe, recent commitments to LRRD have often been renewed under the framework of resilience programming, with donors in particular suggesting that LRRD potentially provides an organising principle that can support the operationalisation of resilience strategies (European Parliament, 2012; Mosel \& Levine, 2014; OECD, 2012; VOICE and CONCORD, 2012). This is a notable proposition, given that practice integration within LRRD programs themselves remains poorly explicated. Few specific tools or guidelines to support LRRD have been developed, and recognised examples of program applications are limited. Historically, the EU has contributed to these outcomes through a lack of flexibility in its financing instruments, and by not having a common strategic framework between humanitarian and development actors (European Parliament, 2012; Mosel \& Levine, 2014). Recent initiatives such as the Joint Humanitarian Development Framework (JHDF) have been applied particularly in relation to food security programs such as the Supporting Horn of Africa Resilience (SHARE), and are making important progress on longer-term program integration. This has included the development and take-up of new EC financial instruments that offer greater support to such programming, including multiannual allocations, the maintenance of unallocated funds, and 'urgency procedures' that permit finance restructuring in crisis and fragility situations (European Commission, 2007). A range of recent case studies (Ekblad, 2017; Labh \& Pfander, 2011; Pramana, 2012) have also highlighted examples of program design and implementation which reflect successful integration.

Even though Work Stream Ten of the Grand Bargain has been abandoned, there was some notable progress among donors towards LRRD. As the independent report on the Grand Bargain notes (Metcalfe-Hough \& Poole, 2018, pp. 61-63), France has led the way on Commitment 10.1: 'Using existing resources and capabilities to shrink humanitarian needs over the long term with a view to contributing to the outcomes of the Sustainable Development Goals. Significantly increase prevention, mitigation and preparedness for early action to anticipate and secure resources for recovery'. In 2008 France established its Centre de Crise et de Soutien (CDCS), (Ministry for Europe and Foreign Affairs' Crisis and Support Centre), a post-conflict stabilisation unit. Other donors such as Germany and the UK, along with the World Bank, have moved to create a Centre for Global Disaster Protection in 2017, although the extent to which the Grand Bargain deliberations influenced this initiative remains unclear.

Despite the renewed interest in LRRD, and policy and financing instruments that can support its further development, these are yet to be translated into an operational framework that has received broad recognition from international actors (OECD, 2012). This is particularly important given that the need to operationalise resilience frameworks has been seen by many as one of the best opportunities yet for the development of a definitive LRRD approach (European Parliament, 2012; Kildi, 2016; Mosel \& Levine, 2014). While recent exemplar programs have emerged, a critical question remains regarding the extent to which LRRD program information exists in sufficient detail to realistically inform practice integration within resilience interventions. In this context, it is timely to review the existing

Social Science Protocols, December 2018, 1-12. 
evidence base regarding LRRD programs, particularly design and operational aspects, as these are more likely to inform resilience and related frameworks. Critical questions for this review include the extent to which LRRD interventions are operationally defined; how this supports/enables practice at a program level; and whether there are discernible program outcomes related to effective integration of RRD elements.

\subsection{The proposed review question}

The aim of this review is to identify the primary strategies that aid programs employ to link Humanitarian and Development interventions, primarily through the lens of the "Linking Relief Rehabilitation and Development" (LRRD) model. It will examine humanitarian and development interventions following natural disasters and those within protracted political crises. The review will focus on program design and operational levels, rather than structural and institutional levels, and will examine those factors reported to enable such linkages and those that impede effective linkage. Consideration is also given to assessments of beneficiary impact related to such interventions and the implications of these findings for future programming and policy. In order to achieve this aim, four review questions are formulated:

1. What specific strategies do programs employ to link Humanitarian and Development interventions at program planning/design and operational levels?

2. Are the factors that support/enable program outcomes and LRRD operational linkages defined?

3. Are the factors that disenable program outcomes and LRRD operational linkages defined?

4. What are the reported impacts of these interventions (e.g. program assessments, beneficiary impact assessments, developed outcome measures), including specific contributions of effective phase linkage to program outcomes?

\section{Methods}

\subsection{Study design}

This systematic review protocol is informed by the standard Preferred Reporting Items for Systematic review and Meta-Analysis Protocols (PRISMA-P) reporting guidelines (David Moher et al., 2015).

\subsection{Eligibility criteria}

\section{Participants}

The population of focus in the review is those who have been beneficiaries of a programme or policy that explicitly aims to link disaster relief, community rehabilitation and development aid processes. As such, examined beneficiary groups may be in relief, rehabilitation or development settings, as well as transition phases between these states.

\section{Types of interventions}

Eligible interventions for the review will include all programmes that are delivered in a humanitarian and/or development setting with an aim of sustainable development within the LRRD framework. These will include interventions and programmes across livelihoods, health, education and others. The geographical locations of these interventions will not be a limitation and this review will include any intervention that meets these criteria. However, programmes that focus on resilience will be excluded in this review. 


\section{Types of studies}

This systematic review will consider both published and unpublished literature (Mahood, Van Eerd, \& Irvin, 2014). The search will include both qualitative and quantitative study types. Quantitative study types considered will be randomised controlled trials (RCTs), nonrandomised trials, cross-sectional studies and quasi-RCTs. Other studies will be observational, qualitative or mixed-methods. The unpublished grey literature search will include both programme and evaluation reports, and working papers. Editorials, dissertations and theses, conference abstracts, opinion pieces, books and book reviews will not be included (Adams, Smart, \& Huff, 2016). Only studies published in English between 1980 and 2018 will be considered for review. We set 1980 as the base year because LRRD originated in the 1980s during the food security crises in Africa (Mosel \& Levine, 2014).

\section{Outcomes of interest}

Preliminary literature review suggests that there will be considerable heterogeneity in the study outcomes. Therefore, for the purpose of this review outcomes have not been specified $a$ priori. Although they may include understanding the types of LRRD strategies used in programmes, these could be at the programme planning and design stage and/or intervention stage, and the factors that enable or disenable the operational linkage of aid instruments. This review will seek to understand the probable impacts of these LRRD interventions and specific contributions of effective phase linkage to program outcomes.

\section{Search strategy}

The search strategy of this protocol is designed to be as extensive as possible to identify all eligible studies. A multi-step search approach will be used to retrieve relevant studies from eight academic databases. The databases will be searched using a variety of sub headings and free text terms:

Search strategy terms

Development OR Development aid OR development assistance

AND

Humanitarian OR Humanitarian aid OR disaster OR crises OR humanitarian assistance OR relief $O R$ rehabilitation

AND

Link* OR integrat*

AND

Program OR operation* OR strategies OR impact OR intervention* OR evaluation OR assessment

Databases to be searched:

1. Academic OneFile

2. Academic Search Complete (EBSCO)

3. Econlit (EBSCO)

4. JSTOR

5. ProQuest Social Science Journals

6. Scopus (Elsevier)

7. Social Services Abstracts (ProQuest)/Sociological Abstracts/ SocINDEX (EBSCO)

8. Web of Science 
A combination of the above mentioned sub headings and free text words will be used to search grey literature in key organisations' websites, as listed below. This list might be reviewed when undertaking the research.

- 3ie impact assessment

- Australian AID

- European Commission

- ECHO - The Humanitarian Aid Department of European Commission

- DevCo

- Department for International Development (DFID)

- Food and Agriculture Organisation (FAO)

- Institute of Development Studies

- Medicines Sans Frontières

- Oxfam

- Overseas Development Institute

- Red Cross

- United Nations International Children's Emergency Fund (UNICEF)

- United Nations Development Programme (UNDP)

- United States AID

- United Nations Volunteers (UNV)

- World Vision

In addition, a lateral approach involving a review of reference lists in relevant papers/reviews will be undertaken. Search engines such as Google or Google Scholar will be searched to include any relevant articles and reports.

\subsection{Data collection}

\section{Study selection process}

Studies yielded in the search will be imported into EndNote where duplicates will be identified and removed. The selection of the studies will be done in three steps. Firstly, titles will be screened to remove any irrelevant studies followed by screening of abstracts to confirm eligibility and relevance. After this initial selection, full texts of studies will be reviewed for final inclusion. This process will be undertaken independently by two researchers and with discussion to resolve any disagreements. A third researcher will be consulted in case of any unresolved issues.

\section{Data extraction}

Data extraction will be done using a piloted form, as documented in Table 1. This form has been developed using ten randomly selected studies. The data extracted will mainly include: study details (such as author's name, year of publication) study design, intervention type, study characteristics (including sample setting, population), reported LRRD strategies (program planning / design or field operations), Enabling factors (factors enabling operational linkages (RRD)), Disenabling factors (factors disenabling operational linkages (RRD)), and Impacts (Impacts of intervention [e.g. program assessments, beneficiary impact assessments] and specific contributions of effective phase linkage to program outcomes identified). Grey literature will be extracted using similar details. 
Table 1. Data extraction form.

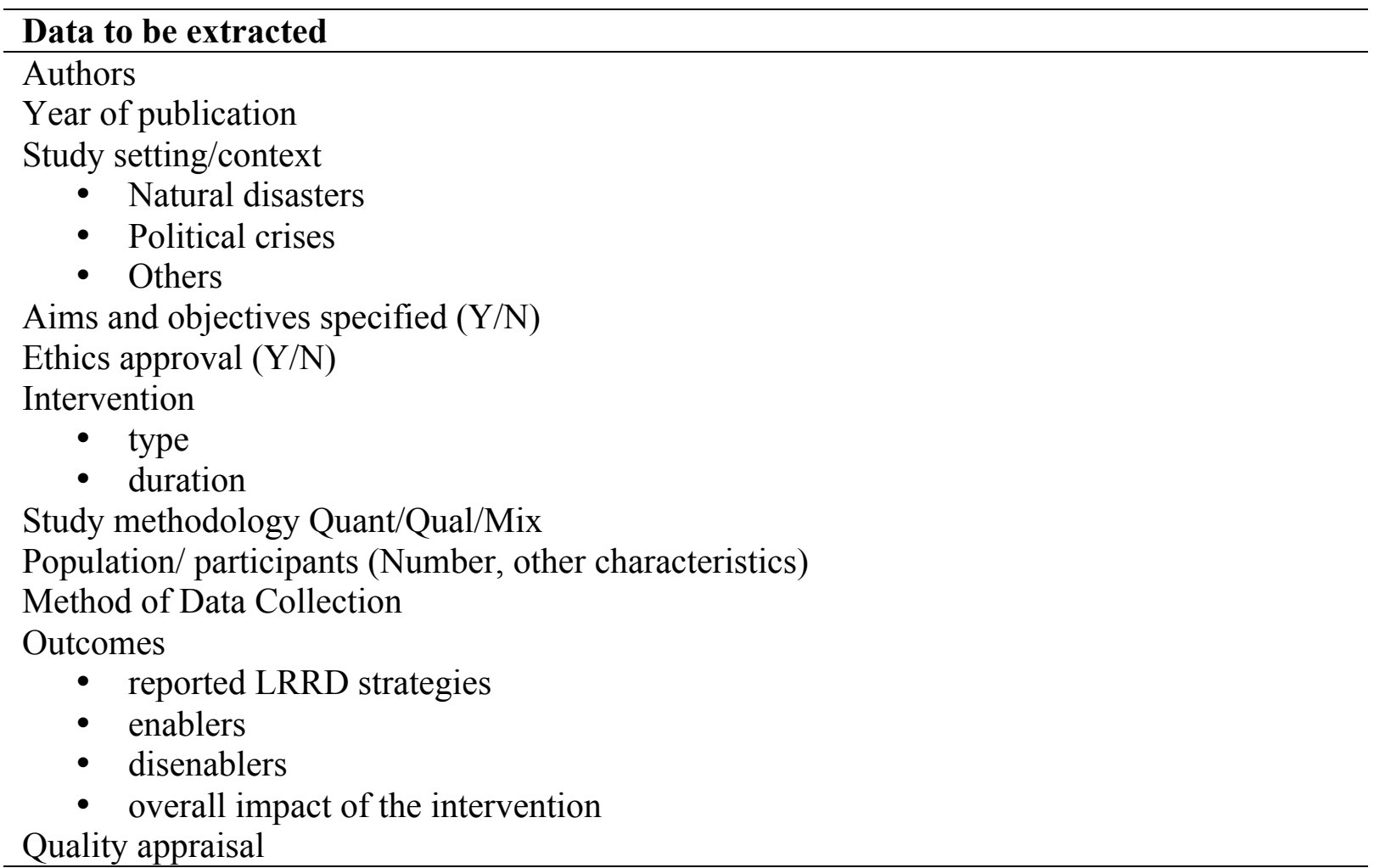

\section{Assessment of methodological quality}

Final included studies will be assessed and scored for methodological quality. The methodological quality of qualitative studies will be evaluated using the Critical Appraisal Skills Programme criteria tool (Critical Appraisal Skills Programme, 2017 ). The Jadad scale will be used to assess the quality of randomised controlled trials based on methods relevant to random assignment, double blinding, and the flow of patients (David. Moher, Jadad, \& Tugwell, 2009). ROBINIS-I tool will be used to assess all other quantitative studies such as non-controlled trials and quasi-experiments (Sterne et al., 2016). Mixed methods studies will be assessed based on the MMAT (mixed methods appraisal tool) by Pluye and colleagues (Pluye et al., 2011), using a three point criteria of objective, data collection and results. MMAT is new and a developing tool but it has substantive theoretical validity, is content validated and has been tested for efficiency and reliability (Pierre Pluye, 2015; Souto et al., 2015). Grey literature will be appraised with the AACODS tool that looks at authority, accuracy, coverage, objectivity, date and significance (Tyndall, 2010). This tool is being widely recognised by academics and researchers for appraisal of grey literature. The quality of all studies will be independently appraised by two researchers and any disagreements will be resolved through discussion. Any further discrepancies will be independently reviewed by the third researcher.

\section{Data synthesis}

Due to the heterogeneity and variation of the studies to be reviewed - especially the study methods, measurements and outcomes, a narrative synthesis of findings will be adapted where common themes will be identified and extracted from both qualitative themes and quantitative narratives to generate insight regarding LRRD. All studies results will be 
aggregated to provide a holistic analysis. The primary researcher will summarise the study findings and narrate the emerging themes. The secondary researcher will review the appropriateness of the content as well as the consistency of the emerging themes. Any disagreements will be reviewed by the third researcher.

\section{Discussion}

There is a renewed interest amongst policy makers, donor communities, development agencies and humanitarian organisations regarding practical applications of LRRD that can support improved and sustainable development and inform practice integration within resilience strategies (European Commission, 2007; European Parliament, 2012; Mosel \& Levine, 2014). Though there has been adequate research of LRRD at policy level to define the concept, little research has been conducted to understand the application of LRRD at operational level and its enabling or disenabling factors (Brusset et al., 2006; Ekblad, 2017; Goyder et al., 2006; Mosel \& Levine, 2014).

Despite the failure of the Grand Bargain on the LRRD front, there is still a pressing need to articulate integration efforts across the humanitarian and development fields. This review will seek to address this critical gap in the literature and provide an important contribution to policy and programming. Findings from this review can also be used to develop an integration framework or metric, such as an audit tool, to quantify the extent or quality of Relief, Rehabilitation and Development integrations. This will enable practical understanding of LRRD in development and humanitarian programs and complement our understanding of resilience frameworks.

We anticipate some limitations in the review, such as the exclusion of studies published in languages other than English. Exclusion of such studies could lead to missing key literature generated by non-English-speaking researchers and regional organisations. This limitation is addressed, in part, by expanding the search to include relevant grey literature documents from International organisations working in humanitarian and development programs. This review does not limit itself to any geographical location, so as to holistically capture the work of LRRD across geographies.

\section{Declarations}

Acknowledgements: This research is being conducted by the Humanitarian and Development Research Initiative (HADRI) at the School of Social Sciences and Psychology, Western Sydney University.

\section{References}

Adams, R. J., Smart, P., \& Huff, A. S. (2016). Shades of Grey: Guidelines for working with the grey literature in systematic reviews for management and organizational studies. International Journal of Management Reviews, 19(4), 432-454. doi:10.1111/ijmr.12102

Botha, D., \& van Niekerk, D. (2013). Views from the Frontline: A critical assessment of local risk governance in South Africa. Jàmbá, 5(2), 1-10. Retrieved from http://dx.doi.org/10.4102/jamba.v5i2.82 
Brusset, E., Pramana, W., Davies, A., Deshmukh, Y., \& Pedersen, S. (2006). Links between Relief, Rehabilitation and Development in the Tsunami Response: Indonesia Case Study. Retrieved from https://www.sida.se/contentassets/6aa1638098544347b7b2f782308345e6/links-betweenrelief-rehabilitation-and-development-in-the-tsunami-response_3145.pdf

Christoplos, I., Novaky, M., \& Aysan, Y. (2012). Resilience, risk and vulnerability at Sida. Retrieved from https://www.sida.se/contentassets/5de4b5ba77044012af09ba3eb53f3a5f/resilience-riskand-vulnerability-at-sida---final-report_3406.pdf

Critical Appraisal Skills Programme. (2017). Ten questions to help you make sense of qualitative research. Retrieved from http://docs.wixstatic.com/ugd/dded87_25658615020e427da194a325e7773d42.pdf

Duffield, M. (1994). Complex emergencies and the crisis of developmentalism. Institute of Development Studies Bulletin, 25(4).

Ekblad, P. (2017). Bridging the humanitarian-development fivide: Indonesian-Swedish stakeholder case studies on LRRD. (Master program in International Humanitarian Action Masters thesis), Uppsala University. Retrieved from http://www.divaportal.org/smash/get/diva2:1121069/FULLTEXT01.pdf

European Commission. (2007). Communication from the commission to the European parliament and the council: Towards a European consensus on humanitarian aid. Retrieved from http://ec.europa.eu/echo/files/policies/consensus/acte_en.pdf

European Parliament. (2012). Policy briefing: Linking relief, rehabilitation and Development, directorate-general for erxternal policies. Retrieved from http://www.europarl.europa.eu/RegData/etudes/briefing_note/join/2012/491435/EXPODEVE_SP(2012)491435_EN.pdf

Goyder, H., Coventry, C., Adams, J., Kaiser, T., Williams, S., \& Smillie, I. (2006). Links between relief, rehabilitation and development in the Tsunami response: Policy study. Retrieved from https:/www.humanitarianlibrary.org/sites/default/files/2014/02/1rrdpolicy-study.pdf

Harmer, A., \& Macrae, J. (2004). Beyond the continuum: The changing role of aid policy in protracted crises. Retrieved from https://www.odi.org/sites/odi.org.uk/files/odiassets/publications-opinion-files/279.pdf

Jones, S., Oven, K. J., Manyena, B., \& Aryal, K. (2014). Governance struggles and policy processes in disaster risk reduction: A case study from Nepal. Geoforum, 57, 78-90. Retrieved from https://doi.org/10.1016/j.geoforum.2014.07.011

Khalil, J., \& Zeuthen, M. (2014). A case study of counter violent extremism (CVE) programming: Lessons from OTI's Kenya transition initiative. Stability: International Journal of Security and Development, 3(1). Retrieve from http://doi.org/10.5334/sta.ee

Kildi, J. (2016). Linking relief, rehabilitation and development in South Sudan: missed opportunities of the European Commission? Paper presented at the International Conference on Economics, Political and Law Science, Rome, Italy.

Labh, N., \& Pfander, B. (2011). Implementing the linking relief, rehabilitation and development (LRRD) approach in the post-earthquake rehabilitation project in Gujarat, India. Retrieved from https://www.redcross.ch/it/file/12371/download

Longhurst, R. (1994). Conceptual frameworks for linking relief and development. Institute of Development Studies Bulletin, 25(4). Retrieved from https://opendocs.ids.ac.uk/opendocs/bitstream/handle/123456789/9324/IDSB_25_4_10.11 11-j.1759-5436.1994.mp25004003.x.pdf?sequence $=1$ 
Macrae, J. (2012). 'The continuum Is dead, long Live resilience'. Retrieved from https://ngovoice.org/publications/voice-out-loud-15-lrrd.pdf

Mahood, Q., Van Eerd, D., \& Irvin, E. (2014). Searching for grey literature for systematic reviews: challenges and benefits. Research Synthesis Methods, 5(3), 221-234. doi:10.1002/jrsm.1106

Metcalfe-Hough, V., \& Poole, L. (2018). Grand bargain annual independent report 2018: HPG Commissioned Report. Retrieved from https://www.agendaforhumanity.org/sites/default/files/resources/2018/Jun/Grand\%20Barg ain\%20annual $\% 20$ independent $\% 20$ report $\% 202018$ full.pdf

Moher, D., Jadad, A. R., \& Tugwell, P. (2009). Assessing the quality of randomized controlled trials: Current issues and future directions. International Journal of Technology Assessment in Health Care, 12(2), 195-208. doi:10.1186/2046-4053-4-1

Moher, D., Shamseer, L., Clarke, M., Ghersi, D., Liberati, A., Petticrew, M., . . Group, P.-P. (2015). Preferred reporting items for systematic review and meta-analysis protocols (PRISMA-P) 2015 statement. Systematic Reviews, 4(1), 1.

Morazán, P., Grünewald, F., Knoke, I., \& Schäfer, T. (2012). Strengthening the link between relief, rehabilitation and development (LRRD) in the EU's financing instruments for development and humanitarian aid under the MFF 2014-220. Retrieved from $\mathrm{http}: / / \mathrm{www}$.europarl.europa.eu/thinktank/en/document.html?reference=EXPODEVE_ET\%282012\%29433783

Mosel, I., \& Levine, S. (2014). Remaking the case for linking relief, rehabilitation and development: How LRRD can become a practically useful concept for assistance in difficult places. Retrieved from https://www.odi.org/sites/odi.org.uk/files/odiassets/publications-opinion-files/8882.pdf

OECD. (2012). Review of the development cooperation policies and programmes of the European Union, Secretariat Report. Retrieved from http://www.oecd.org/dac/peerreviews/1935386.pdf

Otto, R., \& Weingärtner, L. (2013). Linking relief and development: More than old solutions for old problems. Retrieved from https://www.government.n1/documents/reports/2013/05/01/iob-study-linking-relief-anddevelopment-more-than-old-solutions-for-old-problems

Pluye, P. (2015). Mixed kinds of evidence: synthesis designs and critical appraisal for systematic mixed studies reviews including qualitative, quantitative and mixed methods studies. Evidence Based Medicine, 20(2), 79. doi: 10.1136/ebmed-2014-110158

Pluye, P., Robert, E., Cargo, M., Bartlett, G., O'Cathain, A., Griffiths, F., . . Rousseau, M. C. (2011). Proposal: A mixed methods appraisal tool for systematic mixed studies reviews. Retrieved from http://mixedmethodsappraisaltoolpublic.pbworks.com/w/file/fetch/84371689/MMAT\%20 2011\%20criteria\%20and\%20tutorial\%202011-06-29updated2014.08.21.pdf

Pramana, W. (2012). Linking relief, rehabilitation and development (LRRD): lessons learned from the Australian and the Canadian Red Cross waste management program in the Maldives WIT Transactions on Ecology and the Environment, 140. doi: 10.2495/WM100231

Souto, R. Q., Khanassov, V., Hong, Q. N., Bush, P. L., Vedel, I., \& Pluye, P. (2015). Systematic mixed studies reviews: Updating results on the reliability and efficiency of the mixed methods appraisal tool. International Journal of Nursing Studies, 52(1), 500-501. doi:https://doi.org/10.1016/j.ijnurstu.2014.08.010 
Steets, J. (2011). Donor strategies for addressing the transition gap and linking humanitarian and development assistance: a contribution to the international debate. Retrieved from http://www.gppi.net/fileadmin/user_upload/media/pub/2011/steets_2011_transition_web.p df

Sterne, J. A. C., Hernán, M. A., Reeves, B. C., Savović, J., Berkman, N. D., Viswanathan, M., . . Higgins, J. P. T. (2016). ROBINS-I: a tool for assessing risk of bias in nonrandomised studies of interventions. BMJ, 355. doi: https://doi.org/10.1136/bmj.i4919

Twigg, J. (2015). Disaster risk reduction. Retrieved from https://goodpracticereview.org/wpcontent/uploads/2015/10/GPR-9-web-string-1.pdf

Tyndall, J. (2010). AACODS Checklist. Retrieved from https://dspace.flinders.edu.au/jspui/bitstream/2328/3326/4/AACODS_Checklist.pdf

VOICE and CONCORD. (2012). Linking relief rehabilitation and development (LRRD): Towards a more joined up approach enhancing resilience and impact. Retrieved from https://reliefweb.int/sites/reliefweb.int/files/resources/VOICE\%20CONCORD\%20positio n\%20paper\%20Linking\%20Relief\%20Rehabilitation\%20and\%20DevelopmentJuly\%202012.pdf 